\title{
An evaluation of the knowledge of pediatric nurses about the oral health status of newborns and pediatric oral health care
}

\author{
Illknur Kahriman*1, Havva Karadeniz², Tamer Tüzüner ${ }^{3}$, Adem Kușgöz ${ }^{3}$ \\ ${ }^{1}$ Department of Pediatric Nursing, Faculty of Health Sciences, Karadeniz Technical University, Trabzon, Turkey \\ ${ }^{2}$ Department of Public Health Nursing, Faculty of Health Sciences, Karadeniz Technical University, Trabzon, Turkey \\ ${ }^{3}$ Department of Pediatric Dentistry, Faculty of Dentistry, Karadeniz Technical University, Trabzon, Turkey
}

Received: January 18, 2017

DOI: $10.5430 /$ cns.v5n2p53
Accepted: April 17, 2017

Online Published: May 3, 2017

URL: https://doi.org/10.5430/cns.v5n2p53

\begin{abstract}
Objective: The purpose of this study is to evaluate the knowledge of pediatric nurses about the oral health care of newborns and children.

Methods: Seventy-one pediatric nurses working in newborn and pediatric units were recruited to the study. After receiving approval from the source and ethical committee, the survey questions were derived from the source of National Maternal and Child Oral Health Resource Center (OHRC) in Georgetown University and then translated into Turkish. The survey consists of demographic questions and 7 different categories of 48 questions related with oral health status of newborns and pediatric oral health care. The correct and wrong answers were recorded as " 1 " and " 0 " point for each question respectively. Total correct answers were calculated between 0-48 for each participant. The descriptive analysis and multiple linear regression model was used for statistical evaluations $(p<.05)$.

Results: The average of correct answers was found as $17.72 \pm 6.5$. According to the multiple linear regression model, all categories including the nurses' knowledge $(p<.001)$, educational status $(p=.019)$, years of professional experience $(p=.001)$ and their previous education on oral health care $(p=.013)$ showed significant effects on the total amount of correct answers.

Conclusions: The knowledge of the nurses regarding the oral health status of newborns and pediatric oral health care was found relatively low. The nurses' low educational status, years of professional experience, and inadequate previous education on oral health care may be considered as risk factors for their lack of knowledge.
\end{abstract}

Key Words: Oral health knowledge, Pediatric nurses, Early childhood caries, Newborns, Infants, Pediatric

\section{INTRODUCTION}

Early childhood caries (ECC) is defined as the presence of one or more decayed (noncavitated or cavitated lesions), missing (due to caries), or filled tooth surfaces in any primary tooth in a child aged 71 months or younger. ${ }^{[1]}$ ECC in young children is often treated under general anaethesia, which may incur both risk and higher cost. ${ }^{[2-4]}$

Oral health is associated with quality of life, and behavioural and cognitive development, and untreated caries commonly disrupts the growth and development of children. ${ }^{[5-7]}$ Therefore, early diagnosis of caries, oral health-related issues and prevention of them in infants, toddlers, and older age groups

*Correspondence: İlknur Kahriman; Email: ilknurkahriman@ hotmail.com; Address: Department of Pediatric Nursing, Faculty of Health Sciences, Karadeniz Technical University, Trabzon, Turkey. 
may be a critical solution to reduce the oral health related risks. ${ }^{[8,9]}$ In most countries, nurses are the health professionals who are regularly in contact with infants, toddlers, children and their parents from the birth. ${ }^{[10,11]}$

In order to enhance the chance of preventing oral healthrelated issues as well as raising awareness about normal and pathological dental conditions among children, primary health care nurses have been considered a cost-effective worker group in oral health screening and education procedures for regular dental visits. ${ }^{[11-17]}$

In general, basic education principles of nursing students and/or nurses do not contain specific oral health issues, which results in inadequate knowledge on the oral health care of newborns and children. ${ }^{[11,13-17]}$ Since pediatric nurses could have responsibilites for preventive dentistry and recognition of caries progression from the first eruption of primary teeth, as well as monitoring the development of oral and maxillo facial region in the pediatric population ${ }^{[4,8,12-17]}$ professional education strategies might be implemented into their basic education courses which could also be beneficial to manage the oral health profile of newborns and children.

According to our knowledge, there are not any professional education modules and/or test questionnaires for pediatric nurses both in our country and in the literature 16 regarding the oral health issues of newborns, infants and/or toddlers. However, different education strategies and modules have been described in the literature, such as American Academy of Pediatrics and Maternal Child Health Resources for Pediatric Nurses ${ }^{[18,19]}$ which also contains test questions to measure the effectiveness of previously given education. ${ }^{[19]}$ "Sohn et al. ${ }^{[20]}$ stated that the inadequacy of knowledge regarding oral health issues must be clearly addressed before composing detailed education strategies to nursing students or nurses belonging to certain cultures."

Studies indicate that the majority of nurses have inadequate education and knowledge on oral health care. ${ }^{[11,12,16,17]}$ In addition, the current evidence supports the idea of improving knowledge quality of these health professionals with different education strategies.

The aim of this study is to evaluate the knowledge of a group of pediatric nurses working in medical faculty regarding the oral health status of newborns and pediatric oral care and to attract the attention to this area for further planning.

\section{SUBJECTS AND METHODS}

\subsection{Data collection}

The study was approved by the Karadeniz Technical University (KTU) Committee on Human Research (Approval number 2015/93). 71 pediatric nurses recently working in newborn and pediatric clinics at KTU Faculty of Medicine in June 2015-July 2016 were included in the study. A written consent form was obtained from the participants. The survey questions were derived from the source of National Maternal and Child Oral Health Resource Center (OHRC) in Georgetown University after receiving the permission from the source. ${ }^{[19]}$

\subsection{Research design}

The questionnaire was first sent to a professional translator and it was then evaluated by Turkish-speaking authors who adjusted statements when necessary. A pilot study of the Turkish version of the questionnaire was performed with 10 nurses who did not participate in its final version. Following the word improvement, the final version was retested among 10 nurses and, once approved, was translated back to English by one of the researchers. The suitability of the final version was checked by a professional translator comparing with the original version.

The data included demographic variables such as age, marital status, parental status, the type of high school, education level, the type of pediatric clinic in which the nurses work, years of professional experience as a nurse, the duration of working in the same clinic, and previous education regarding the oral health status of newborn and pediatric oral health care. The survey had 7 different categories of 48 questions covering the following issues: "an introduction to infants and young children's oral health", "oral conditions and abnormalities", "prevention of oral diseases", "non-nutritive sucking habits", "oral injury" and "infants and young children with special health care needs". The continuous variables as age, years of professional experience, the duration of working life in the same clinic, and total correct answers were given as mean $\pm S D$. Categorical and nominal variables (marital status, parental status, the type of high school, education level, and previous education regarding the oral health status of newborn and pediatric oral health care) were recorded as percentages. The correct and wrong answers were recorded as " 1 " and " 0 " point for each question respectively. Total correct answers were calculated between 0-48 for each participant. The descriptive analysis and multiple linear regression model was used for statistical evaluations $(p<.05)$.

\subsection{Statistical analyses}

The data were analyzed with SPSS for Windows 17.0. The descriptive analysis of demographic variables were recorded as percentages, marital and also the mean $\pm S D$ values of age, years of professional experience as a nurse, the duration of working life in the same clinic and total score of correct answers were obtained. Two different multiple linear regres- 
sion models were used; in both models, the total score of correct answers were selected as the dependent variables. In the first model, demographic variables (dummy variable was obtained when needed) were selected as independent factors (by controlling other questionnaire scores) and in the second model, the subcategories of the survey scores were selected as the independents (by controlling demographic variables). The confidence interval was determined as $95 \%$.

\section{RESUlts}

The mean score of total correct answers was found as $17.72 \pm 6.5$ and the individual mean $\pm S D$ values were given in Table 1. Moreover, the total correct answers were found relatively low since the calculations done between 0 48. According to the first multiple linear regression model, all categories showed similar significant effect $(p<.001)$ on the total correct answers (see Table 2). The details of age, gender status, years of professional experience as a nurse, and the duration of working years in the same clinic were given in Table 3 as mean $\pm S D .53 .5 \%$ nurses were determined to be married and $40.8 \%$ had children. The high school type of the participants was mostly found as Standard High School (54.9\%) and Health Vocational High School $(26.8 \%)$. As for the general education level, the majority of the nurses were found as under graduate- 4 years level $(71.8 \%)$. Most of the nurses $(26.8 \%)$ were determined to be working at newborn clinic and $88.7 \%$ of them did not have any previous education regarding the oral health status of newborn and pediatric oral health care.

The educational status ( $p=.019)$, years of professional experience $(p=.001)$ and previous education regarding oral health care $(p=.013)$ showed significant effects on the total amount of correct answers (see Table 4).

Table 1. The scores of oral health knowledge of pediatric nurses for each category and total correct answers (mean $\pm S D$ )

\begin{tabular}{lll}
\hline Category & Total Question Number & Correct Answers $(\mathbf{m e a n} \pm \mathbf{S D})$ \\
\hline An Introduction to Infants' and Young Children's Oral Health & 4 & $2.31 \pm 1.18$ \\
Managing Infants' and Young Children's Oral Health & 9 & $3.14 \pm 1.33$ \\
Oral Conditions and Abnormalities & 9 & $3.58 \pm 1.70$ \\
Prevention of Oral Disease & 8 & $3.25 \pm 1.91$ \\
Non-Nutritive Sucking Habits & 6 & $1.87 \pm 1.36$ \\
Oral Injury & 8 & $2.18 \pm 1.52$ \\
Infants and Young Children with Special Health Care Needs & 4 & $1.38 \pm 1.02$ \\
\hline Total & 48 & $17.72 \pm 6.5$ \\
\hline
\end{tabular}

Table 2. Multiple linear regression model for categories of survey scores

\begin{tabular}{lll}
\hline Category subject & B & $\boldsymbol{p}$ \\
\hline An Introduction to Infants' and Young Children's & 1 & $<.001$ \\
Oral Health & & \\
Managing Infants' and Young Children's Oral Health & 1 & $<.001$ \\
Oral Conditions and Abnormalities & 1 & $<.001$ \\
Prevention of Oral Disease & 1 & $<.001$ \\
Non-Nutritive Sucking Habits & 1 & $<.001$ \\
Oral Injury & 1 & $<.001$ \\
Infants and Young Children with Special Health Care & 1 & $<.001$ \\
Needs & \multicolumn{2}{c}{} \\
\hline
\end{tabular}

\section{DISCUSSION}

This study confirmed that the oral health care knowledge of a group of pediatric nurses in our medical faculty regarding the oral health status of newborns and pediatric oral health care is relatively low, which is associated with factors such as education level, years of professional experience as a nurse and previous education regarding oral health care.
Sohn et al. ${ }^{[20]}$ stated that the inadequacy of knowledge regarding oral health issues must be clearly addressed before composing detailed education strategies to nursing students or nurses belonging to certain cultures. Pesaressi et al. ${ }^{[16]}$ reported similar results including the poorer knowledge status, particularly in the knowledge of "experience in seeing carious lesions" and "the knowledge on caries prevention". In the literature, it has also been reported that the rudimentary knowledge level of nurses regarding children's oral health care is inevitable due to the fact that education on specific oral health issues has not been implemented in their continuous education period. They also argued that increasing the knowledge status could be ensured by using oral health care training programs and/or inter-professional education for collaborations. ${ }^{[11,17,22]}$ In another study, ${ }^{[21]}$ pediatricians and clinic nurses were enrolled in a 1-hour study training intervention. After the training program, the correct answers about ECC increased from $66 \%$ to $79 \%$ about the ECC. As for our results, nurses $(88.7 \%)$ mostly declared that they did not have previous professional education regarding the 
oral health status of newborns and pediatric oral health care and these results were found highly associated with the total mean score of correct answers in the second multiple linear regression model ( $p=.013$ ) (see Table 4$)$. These outcomes and our findings could probably be explained by the lowlevel knowledge and awareness status of nurses and/or health care professionals about related oral health topics. Although the nurses in our study group have an important role in pediatric oral health care, their knowledge was found to be poor. Therefore, this problem must be solved by implementing professional education strategies during their academic and professional job career planning as stated previously by other authors. $^{[11,13,16,17,20-22]}$ Moreover, the authors of this study have also designed a new project and started a new education training program for nursing students and parents with children aged 0-3 years old using the source of OHRC in Georgetown University since the permissions were also obtained from the source. ${ }^{[19]}$

Table 3. Demographic variables of nurses

\begin{tabular}{|c|c|}
\hline Items & Characteristics \\
\hline Age (mean \pm SD) & $32.18 \pm 6.74$ \\
\hline \multicolumn{2}{|l|}{ Gender (\%) } \\
\hline Female/Male & $100 / 0$ \\
\hline \multicolumn{2}{|l|}{ Marital status (\%) } \\
\hline Yes/No & $53.5 / 46.5$ \\
\hline \multicolumn{2}{|l|}{ Parental status (\%) } \\
\hline Yes/No & $40.8 / 59.2$ \\
\hline \multicolumn{2}{|l|}{ Type of high school (\%) } \\
\hline $\begin{array}{l}\text { Standard high school/Vocational High School/Anatolian High School/Health vocational } \\
\text { high school }\end{array}$ & $54.9 / 8.5 / 9.9 / 26.8$ \\
\hline \multicolumn{2}{|l|}{ Education level (\%) } \\
\hline High School/Undergraduate-4 years/Graduate-6 years/Post Graduate & $12.7 / 12.7 / 71.8 / 2.8$ \\
\hline \multicolumn{2}{|l|}{ Type of pediatric clinic in which the nurse work (\%) } \\
\hline $\begin{array}{l}\text { Newborn/Pediatric surgery/Adolescent/Pediatric emergency/Nurseling clinic/Pediatric } \\
\text { policlinic/Pediatric intenstive care /Pediatric infection/Pediatric hematology }\end{array}$ & 26.8/9.9/7.0/9.9/8.5/7.0/11.3/9.9/9.9 \\
\hline Years of professional experience as a nurse (mean \pm SD) & $9.76 \pm 6.87$ \\
\hline The duration of working life in the same clinic (mean \pm SD) & $6.80 \pm 4.70$ \\
\hline \multicolumn{2}{|l|}{$\begin{array}{l}\text { Previous education regarding the oral health status of new born and pediatric oral } \\
\text { health care (\%) }\end{array}$} \\
\hline Yes/No & $11.3 / 88.7$ \\
\hline
\end{tabular}

Table 4. Multiple linear regression model for demographic variables

\begin{tabular}{llc}
\hline & B & $\boldsymbol{p}$ \\
\hline Education level & 2.211 & .001 \\
$\begin{array}{l}\text { Years of professional experience as a nurse } \\
\text { Previous education regarding the oral health }\end{array}$ & 0.324 & .019 \\
status of new born and pediatric oral health care & -5.369 & .013 \\
\hline
\end{tabular}

In the literature, contradictory results have been obtained from some studies in which education degree is found a significantly effective factor whereas years of professional experience did not significantly influence knowledge. ${ }^{[11]}$ Perassi et al. ${ }^{[16]}$ also indicated no significant associations between knowledge vs. socio-economic status and years of professional experience in their study. When considering socio- demographic factors, we did not obtain any significant relations between age, marital status, parental status, type of high school, type of pediatric clinic in which the nurses work, the duration of working life in the same clinic and total mean correct scores. However, the percentage of undergraduate education level was found considerably high $(71.8 \%)$ compared with the others and the average years of professional experience as a nurse was found as $9.76 \pm 6.87$ (see Table 4). These factors were also found significantly related (education level; $p=.001$ and years of professional experience as a nurse; $p=.019$ ) with the mean total correct answer scores (see Table 4). Increased knowledge status with the higher education level and the years of professional experience could probably be related with the better experience and awareness status of these nurses. 
Moreover, our study group is limited to a staff group of our medical faculty. Since this is an only a short-term crosssectional study, designing further studies with larger samples, specifically with newborns and primary oral health care nurses, could provide more representative outcomes to describe the effects of such confounding factors on oral health related knowledge properties.

\section{Conclusions}

The knowledge of a nurse group regarding the oral health status of newborns and pediatric oral health care was found to be relatively low. Factors such as low educational status, and years of professional experience and inadeqaute previous education regarding oral health care might be considered as risk factors for the lack of knowledge. Nurses could attend the continous education programmes and/or courses regarding the oral health status of newborns and pediatrics. These education programmes could facilitate their managing skills when they are exposed to these age groups and also improve their communication properties with parents and dentists with respect to conduct proper oral health status. Since nurses are in intimate contact with parents, infants, toddlers and children before dentists, further studies need to evaluate the knowledge status of larger nurse groups and implement comprehensive knowledge and training programmes into their professional practice areas.

\section{CONFlicts of InTEREST Disclosure}

The authors declare they have no conflict of interest.

\section{REFERENCES}

[1] American Academy of Pediatric Dentistry. Policy on early childhood caries (ECC): Classifications, consequences, and preventive strategies (revised 2011). Pediatr Dent. 2012; 34: 50-2.

[2] Alcaino E, Kilpatrick NM, Smith ED. Utilization of day stay general anesthesia for the provision of dental treatment to children in New South Wales, Australia. Int J Pediatric Dent. 2000; 10: 206-12. https://doi.org/10.1046/j.1365-263x.2000.00193.x

[3] Harris R, Nicoll AD, Adair PM, et al. Community Dent Health. 2004; 21: 71-85. PMid: 15072476.

[4] Kagihara LE, Niederhauser VP, Stark M. Assessment, management, and prevention of early childhood caries. J Am Acad Nurse Pract. 2009; 21: 1-10. PMid: 19125889. https ://doi.org/10.1111/j . 1745-7599.2008.00367.x

[5] Casamassimo PS, Thikkurissy S, Edelstein BL, et al. Beyond the dmft: the human and economic cost of early childhood caries. J Am Dent Assoc. 2009; 140: 650-7. PMid: 19491160. https: //doi.org/10.14219/jada.archive.2009.0250

[6] Sheiham A. Dental caries affects body weight, growth and quality of life in pre-school children. Br Dent J. 2006; 201: 625-6. PMid: 17128231. https://doi.org/10.1038/sj.bdj.4814259

[7] Edelstein B, Vargas CM, Candelaria D, et al. Experience and policy implications of children presenting with dental emergencies to US pediatric dentistry training programs. Pediatr Dent. 2006; 28: 431-7. PMid: 17036709.

[8] Olatosi OO, Inem V, Sofola OO, et al. The prevalence of early childhood caries and its associated risk factors among preschool children referred to a tertiary care institution. Niger J Clin Pract. 2015; 18 : 493-501. PMid: 25966721. https ://doi .org/10.4103/1119-3 077.156887

[9] Sofola OO, Folayan MO, Oginni AB. Changes in the prevalence of dental caries in primary school children in Lagos State, Nigeria. Niger J Clin Pract. 2014; 17: 127-33. PMid: 24553018. https: //doi.org/10.4103/1119-3077.127419

[10] Jesmin S, Thind A, Sarma S. Does team-based primary health care improve patients' perception of outcomes? Evidence from the 2007-08 Canadian Survey of Experiences with Primary Health Policy. 2012; 105: 71-83.

Published by Sciedu Press
[11] Rabiei S, Mohebbi SZ, Yazdani R, et al. Primary care nurses' awareness of and willingness to perform children's oral health care. BMC Oral Health. 2014; 26: 26. PMid: 24670004. https : //doi.org/10.1186/1472-6831-14-26

[12] Gussy MG, Waters EB, Riggs EM, et al. Parental knowledge, beliefs and behaviours for oral health of toddlers residing in rural Victoria. Aust Dent J. 2008; 53: 52-60. PMid: 18304242. https : //doi.org/10.1111/j.1834-7819.2007.00010.x

[13] Hallas D, Fernandez J, Lim L, et al. Nursing strategies to reduce the incidence of early childhood caries in culturally diverse populations. J Pediatr Nurs. 2011; 26: 248-56. PMid: 21601149. https : //doi.org/10.1016/j.pedn.2009.07.010

[14] Arrow P, Raheb J, Miller M. Brief oral health promotion intervention among parents of young children to reduce early childhood dental decay. BMC Public Health. 2013; 13: 245. PMid: 23509932. https://doi.org/10.1186/1471-2458-13-245

[15] Smith GA, Riedford K. Epidemiology of early childhood caries: clinical application. J Pediatr Nurs. 2013; 28: 369-73. PMid: 22608944. https://doi.org/10.1016/j.pedn.2012.04.005

[16] Pesaressi E, Villena RS, van der Sanden WJ, et al. Barriers to adopting and implementing an oral health programme for managing early childhood caries through primary health care providers in Lima, Peru. BMC Oral Health. 2014; 14: 17. PMid: 24597792. https://doi.org/10.1186/1472-6831-14-17

[17] Czarnecki GA, Kloostra SJ, Boynton JR, et al. Nursing and dental students' and pediatric dentistry residents' responses to experiences with interprofessional education. J Dent Educ. 2014; 78: 1301-12. PMid: 25179927.

[18] American Academy of Pediatrics. Oral health risk assessment training for pediatricians and other child health professionals. Available from: http://www . aap.org/healthtopics/oralhealth.cfm

[19] Maternal Child Health. A Health Professional's Guide to Pediatric Oral Health Management is a distance learning program of seven self-contained online modules for health professionals in managing the oral health of infants and young children. Available from: http://www.mcoralhealth.org./PediatricOH/index.htm

[20] Sohn W, Ismail AI, Tellez M. Efficacy of educational interventions targeting primary care providers' practice behaviors: an overview of 
published systematic reviews. J Pub Health Dent. 2004; 64: 164-72. https://doi.org/10.1111/j.1752-7325.2004.tb02747.x

[21] Kressin NR, Nunn ME, Singh H, et al. Pediatric clinicians can help reduce rates of early childhood caries: effects of a practice based intervention. Med Care. 2009; 47: 1121-8. PMid: 19786919.
https://doi.org/10.1097/MLR.0b013e3181b58867

[22] Hallas D, Fernandez JB, Herman NG, et al. Identification of Pediatric Oral Health Core Competencies through Interprofessional Education and Practice. Nurs Res Pract. 2015; 2015: 360523 https://doi.org/10.1155/2015/360523 